\title{
Pesquisa de anticorpos contra arbovírus e o vírus vacinal da febre amarela em uma amostra da população de Rio Branco, antes e três meses após a vacina 17D
}

\author{
Serologic survey for yellow fever and other arboviruses among inhabitants of \\ Rio Branco, Brazil, before and three months after receiving \\ the yellow fever 17D vaccine
}

\author{
José Tavares-Neto ${ }^{1}$, Juliano Freitas-Carvalho ${ }^{1}$, Márcio Roberto Teixeira Nunes ${ }^{2}$, Grace Rocha ${ }^{3}$, \\ Sueli Guerreiro Rodrigues ${ }^{2}$, Edilândio Damasceno ${ }^{2}$, Recleides Darub ${ }^{3}$, \\ Sebastião Viana ${ }^{3}$ e Pedro Fernando da Costa Vasconcelos $\quad 2$
}

\section{RESUMO}

Em amostra da população da cidade de Rio Branco (Acre), foi pesquisada a freqüência de portadores de anticorpos contra os arbovírus, mais prevalentes na região amazônica, e o vírus vacinal da febre amarela, antes e após a imunização com a vacina 17D. Das 390 pessoas incluidas na primeira fase do estudo (agosto de 1999), somente 190 compareceram em janeiro de 2000, três meses após a aplicação da vacina $17 D$ (outubro de 1999). Nas amostras da primeira fase, as freqüências de soropositivos (IH) para os vírus estudados foram: $17 D$ (27,2\%); Dengue-1 (0,3\%); Dengue-2 (4,1\%); Dengue-3 (0\%); Dengue-4 (0\%), entre outros 8 vírus. Nas amostras séricas de janeiro (2000), a soroconversão para o 17D foi de 89,7\% (130/145) e 3,2\% (6/ 190) passaram a ter anticorpos contra o sorotipo 3 (DEN-3). Em conclusão, por conta da elevada taxa de cobertura vacinal e de soroconversão há redução significativa do risco de urbanização do vírus da febre amarela na cidade de Rio Branco, apesar de não ser desprezivel a possibilidade de uma nova epidemia de dengue, pelo DEN-3, a semelhança da registrada em 2000 e 2001 pelos sorotipos 1 e 2.

Palavras-chaves : Arbovírus. Febre amarela. Dengue-3. Soroconversão. Acre.

\section{ABSTRACT}

During a yellow fever vaccination campaign among residents of Rio Branco (Acre State), the frequency of HI antibodies to the most prevalent arboviruses in the Amazon region and to yellow fever virus was determined before and three months after immunization with YF 17D vaccine. From 390 inbabitants included in the first phase of serologic survey (August 1999), only 190 provided a second serum sample, after the use of $17 D$ vaccine (January 2000). Among first phase samples, the frequency of HI antibodies was: 17D (27.2\%); Ilheus (5.9\%); Mayaro (5.4\%); Caraparu (4.9\%); Dengue-2 (4.1\%); Oropouche (2.3\%); and Dengue-1 (0.3\%). In the second study phase, the serologic conversion to YF reached $89.7 \%$ among previously negative persons. Serologic conversions were also observed to Ilheus (6.2\%); Dengue-3 (3.2\%); Mayaro (1.1\%); and Oropouche (1.1\%) viruses. In conclusion, considering the high YF antibody rate after vaccination, the risk of urban yellow fever seems insignificant, although the lower prevalence of HI antibodies to dengue viruses, is of concern and inhabitants are under high risk of dengue outbreaks, especially to DEN-3 recently introduced in Brazil, as was observed in 2000 and 2001 with DEN-1 and DEN-2.

Key-words: Arbovirus. Yellow fever. $17 D$ vaccine. Dengue. Acre State

\footnotetext{
1. Faculdade de Medicina da Universidade Federal da Bahia. 2. Instituto Evandro Chagas da Fundação Nacional de Saúde, Belém, PA. 3. Secretaria de Estado da Saúde e Saneamento do Estado do Acre.

Fontes de Financiamento: CNPq, PET-Medicina e SESSACRE/Governo do Acre.

Endereço para correspondência : Prof. José Tavares-Neto. HUPES/Ambulatório Magalhães Netto/3º andar. 40110-170 Salvador, BA.

e-mail: tavaneto@ufba.br

Recebido para publicação em 23/1/2003

Aceito em 13/11/2003
} 
$\mathrm{Na}$ região amazônica brasileira, foram realizados amplos levantamentos sobre a soroepidemiologia dos arbovírus ${ }^{1718}$, onde também foi isolada e ou caracterizada grande parte dos mesmos ${ }^{17181924}$.

Não obstante, na população do Estado do Acre há uma lacuna no conhecimento sobre a soroepidemiologia dos arbovírus e 0 impacto na Saúde Pública ${ }^{17}$, apesar das condições epidemiológicas favoráveis à circulação de arbovírus em decorrência das extensas áreas de florestas tropicais nativas e da grande biodiversidade. Nessa região do Brasil, os estudos arbovirológicos ficaram restritos às investigações iniciais sobre a Febre Negra de Lábrea ${ }^{6}$ e de tentativas de isolamento viral em animais (aves, répteis e mosquitos) coletados no município de Sena Madureira ${ }^{78}$. Mais recentemente, em janeiro de 2001, ocorreu a incidência máxima da epidemia de dengue pelos sorotipos 1 e 2 (DEN-1 e DEN-2) nas cidades do Vale do Rio Acre, especialmente na capital do Estado (Rio Branco). Isto, após o registro crescente de casos de dengue ao longo do segundo semestre de $2000^{4}$. Anteriormente, em novembro de 1999, houve registro dos primeiros casos de dengue na cidade boliviana de Cobija, vizinha às cidades acreanas de Brasiléia e Epitaciolância $a^{4}$.

Essa situação do Estado do Acre motivou o presente estudo soroepidemiológico sobre os principais arbovírus descritos na região amazônica, em uma amostra da população da cidade de Rio Branco, antes (agosto de 1999) da vacinação em massa contra 0 vírus vacinal da febre amarela (17D) em 10 de outubro de 1999 e da ocorrência da epidemia de dengue em 2000/2001.

\section{MATERIAL E MÉTODOS}

No primeiro dia da Campanha Estadual de Vacinação contra 0 vírus da hepatite B (VHB), em 14 de agosto de 1999, foram selecionadas 394 pessoas residentes na área urbana da cidade de Rio Branco (Acre), com 2 ou mais anos de idade, entre aquelas que compareceram a um dos 212 Postos de Vacinação (temporários) da cidade. Em cada Posto de Vacinação foi selecionada de uma a duas pessoas para coleta da amostra sangüínea e levantamento de informações demográficas e sobre a vacinação prévia contra 0 vírus vacinal (17D) da febre amarela, após conhecer os objetivos da pesquisa e assinar o termo de consentimento livre e esclarecido. A primeira pessoa selecionada era aquela da fila para vacinação que estava sendo atendida (ainda na fase de preenchimento dos dados pessoais), quando da chegada da equipe da pesquisa ao Posto de Vacinação. Nos Postos de Vacinação com mais de 30 pessoas na fila, foi selecionada a outra pessoa subseqüente na fila, desde que não-membro da família da primeira. Quando houve recusa de alguma pessoa (no total de dois casos), foi incluída a pessoa seguinte na fila para vacinação $0^{2}$.

Em seguida ao preenchimento do questionário, foram coletados de 8 a 10ml de sangue venoso sem anticoagulante. Em seguida, as amostras sangüíneas foram centrifugadas e estocadas $\left(-20^{\circ} \mathrm{C}\right)$ no LACEN- AC, onde foram conservadas até o envio para o Laboratório de Arbovírus do Instituto Evandro Chagas (Belém, PA), para a pesquisa de anticorpos inibidores da hemaglutinação (IH), pela técnica de Clarke \& Casals modificada por Shope ${ }^{21}$, dos seguintes arbovírus: Alphavirus da família Togaviridae (vírus Mayaro e
Mucambo); Flavivirus da família Flaviviridae (vírus Ilhéus, Rocio, Dengue-1, Dengue-2, Dengue-3, Dengue-4, Saint Louis e o vírus vacinal da febre amarela, 17D); e Bunyavirus da família Bunyaviridae (vírus Oropouche, Caraparu e Catu). Esses 13 vírus, nem todos são estritamente arbovírus ${ }^{10}$, foram estudados usando soros-controles, positivos e negativos, padronizados pelo IEC (Belém, PA) e considerando soropositivo a amostra com título recíproco $\geq 20$. Os soropositivos para os sorotipos do vírus da dengue foram considerados como resposta primária ou secundária, de acordo com os critérios da Organização Panamericana de Saúde ${ }^{14}$. (i) primária, quando o título recíproco era $<1.280$ e, simultaneamente, havia ausência de resposta ou títulos 4 vezes menores para os demais sorotipos do dengue ou outros flavivírus; e (ii) secundária, títulos recíprocos iguais ou maiores a 1.280 para todos os sorotipos do dengue e/ou outros flavivírus.

A segunda etapa do estudo foi realizada três (3) meses depois, entre os dias 19 a 21 de janeiro de 2000, após a aplicação da vacina contra o 17D (BIOMANGUINHOS ${ }^{\circledR}$, Rio de Janeiro) no dia 10 de outubro de 2000 em toda a população do Estado do Acre. Oito dias antes do início da segunda etapa, todos os participantes do estudo $(n=394)$ foram convidados, por carta, pela Secretaria de Estado de Sáude e Saneamento do Estado (SESSACRE) para nova coleta de sangue, sendo esclarecido qual o objetivo do estudo (pesquisa sorológica do marcador anti-HBs do VHB e anti-17D), e o motivo, ambos descritos em linguagem acessível ao grande público. Na mesma carta-convite, foi solicitado que a pessoa ou responsável legal levasse a caderneta de vacinação, entregue em agosto de 1999, ou atualizada em outubro e dezembro de 1999 por ocasião, respectivamente, da primeira, segunda (+ a vacina 17D) e terceira doses da vacina contra o vírus da hepatite B. Nessa segunda etapa, após a coleta de nova amostra sangüínea, foram seguidos os mesmos procedimentos anteriores, e preenchido o segundo módulo do questionário (dados pessoais, história de vacinação nos meses anteriores e exame da caderneta de vacinação). Por ocasião da segunda etapa do estudo, ainda não eram conhecidos os resultados dos exames sorológicos da primeira amostra sérica.

As análises estatísticas foram realizadas com auxílio do "software" Statistical Package for Social Science (SPSS). Na análise dos resultados, as pessoas naturais do Estado do Acre e nascidas em municípios da região oriental foram incluídas como sendo da região do Vale do Rio Acre, enquanto que aquelas nascidas em municípios da região central e ocidental do Estado como do Vale do Rio Juruá. Para as variáveis contínuas foram determinadas a média, o desvio-padrão e a mediana, enquanto para as variáveis categóricas as medidas de freqüência. As associações foram consideradas estatisticamente significantes se a probabilidade do erro $\alpha$ foi $\leq 0,05$ ( $\mathrm{p} \leq 5 \%$ ).

\section{RESULTADOS}

Das 394 pessoas incluídas no estudo, quatro foram excluídas porque a primeira amostra sérica foi perdida durante 0 processamento laboratorial ou por ocasião do transporte até Belém (PA). Na segunda etapa do estudo, somente atenderam ao convite $190(48,7 \%)$ pessoas. Os resultados da pesquisa sorológica na 
primeira (de agosto de 1999) e na segunda (de janeiro de 2000) amostras séricas estão descritos na Tabela 1. Todas as respostas sorológicas foram do tipo primária, exceto em 21,7\% (23/106) dos 17D-positivos (agosto de 1999) e que foi secundária para dois ou mais flavivírus.

Tabela 1 - Freqüências de anticorpos contra o vírus vacinal da febre amarela (FA-17D) e arbovírus em moradores da cidade de Rio Branco (Acre), antes (agosto de 1999) e depois da vacinação contra o $17 D$ (outubro, 2000)

\begin{tabular}{|c|c|c|c|c|}
\hline \multirow{3}{*}{ Arbovírus } & \multirow{3}{*}{$\begin{array}{l}\text { Agosto, } 1999 \\
\qquad \begin{array}{c}(\mathrm{n}=390) \\
\mathrm{n}^{\circ}(\%)\end{array}\end{array}$} & \multirow{3}{*}{$\begin{array}{c}\text { De agosto de } 1999, \\
\text { que retornaram em } \\
\text { janeiro de } 2000(\mathrm{n}=190)\end{array}$} & \multicolumn{2}{|c|}{ Janeiro-2000 } \\
\hline & & & negativo & positivo \\
\hline & & & $\mathrm{n}^{0} \quad(\%)$ & $\mathrm{n}^{0} \quad(\%)$ \\
\hline \multirow[t]{2}{*}{ FA (17D) } & $106(27,2)$ & negativo $(\mathrm{n}=145)$ & $15(10,3)$ & $130(89,7)$ \\
\hline & & positivo $(\mathrm{n}=45)$ & 0 & $45(100,0)$ \\
\hline \multirow[t]{2}{*}{ Ilheus } & $23(5,9)$ & negativo $(\mathrm{n}=178)$ & $167(93,8)$ & $11(6,2)$ \\
\hline & & positivo $(\mathrm{n}=12)$ & 0 & $12(100,0)$ \\
\hline \multirow[t]{2}{*}{ Rocio } & $2(0,5)$ & negativo $(n=188)$ & $188(100,0)$ & 0 \\
\hline & & positivo $(\mathrm{n}=2)$ & 0 & $2(100,0)$ \\
\hline \multirow[t]{2}{*}{ Caraparu } & $19(4,9)$ & negativo $(n=184)$ & $184(100,0)$ & 0 \\
\hline & & positivo $(n=6)$ & 0 & $6(100,0)$ \\
\hline \multirow[t]{2}{*}{ Mayaro } & $21(5,4)$ & negativo $(n=178)$ & $176(98,2)$ & $2(1,1)$ \\
\hline & & positivo $(\mathrm{n}=12)$ & 0 & $12(100,0)$ \\
\hline \multirow[t]{2}{*}{ Oropouche } & $9(2,3)$ & negativo $(n=181)$ & $179(100,0)$ & $2(1,1)$ \\
\hline & & positivo $(\mathrm{n}=9)$ & 0 & $9(100,0)$ \\
\hline \multirow[t]{2}{*}{ Catu } & $1(0,3)$ & negativo $(\mathrm{n}=190)$ & $190(100,0)$ & 0 \\
\hline & & positivo $(\mathrm{n}=0)$ & 0 & 0 \\
\hline \multirow[t]{2}{*}{ Mucambo } & $3(0,8)$ & negativo $(\mathrm{n}=189)$ & $189(100,0)$ & 0 \\
\hline & & positivo $(\mathrm{n}=1)$ & 0 & $1(100,0)$ \\
\hline \multirow[t]{2}{*}{ Dengue-1 } & $1(0,3)$ & negativo $(n=190)$ & $190(100,0)$ & 0 \\
\hline & & positivo $(\mathrm{n}=0)$ & 0 & 0 \\
\hline \multirow[t]{2}{*}{ Dengue-2 } & $16(4,1)$ & negativo $(n=186)$ & $186(100,0)$ & 0 \\
\hline & & positivo $(n=4)$ & 0 & $4(100,0)$ \\
\hline \multirow[t]{2}{*}{ Dengue-3 } & $0(0)$ & negativo $(\mathrm{n}=190)$ & $184(96,8)$ & $6(3,2)$ \\
\hline & & positivo $(\mathrm{n}=0)$ & 0 & 0 \\
\hline \multirow[t]{2}{*}{ S. Louis } & $2(0,5)$ & negativo $(n=189)$ & $189(100,0)$ & 0 \\
\hline & & positivo $(\mathrm{n}=1)$ & 0 & $1(100,0)$ \\
\hline
\end{tabular}

Da população estudada em agosto de 1999, quase um terço $(27,2 \%)$ era portadora de anticorpos contra 0 vírus vacinal da febre amarela (17D). Entre os soronegativos $(n=284)$ compareceram na segunda etapa $145(51,1 \%)$ pessoas e do grupo de soropositivos $(n=106) 45(42,4 \%)$ atenderam o convite, sendo essas diferenças sem significado estatístico $\left(\chi^{2}=2,78 ; p>0,09\right)$. Na segunda etapa, a soroconversão (três meses após a vacina 17D) foi de 89,7\% (130/ 145) e os 45 soropositivos (da amostra de agosto de 1999), pesquisados em janeiro de 2000, tiveram o mesmo resultado sorológico anterior.

A soroprevalência dos portadores de anticorpos contra os arbovírus pesquisados (Tabela 1), foi inferior a $6 \%$, inclusive para o Oropouche (2,3\%), Mayaro (5,4\%) e Ilhéus (5,9\%), entre outros. Chama a atenção, as freqüências de soropositivos, nas amostras de agosto de 1999, contra os sorotipos do vírus da dengue, DEN-1, DEN-2, DEN-3 e DEN-4, respectivamente: $0,3 \% ; 4,1 \% ; 0 \%$ e $0 \%$. No entanto, cinco meses após (janeiro de 2000) da primeira amostra sangüínea (em agosto de 1999), todos os soronegativos (DEN-1, DEN-2 e DEN-3) pesquisados assim permaneceram, mas 3,2\% (6/190) daqueles soronegativos para o DEN-3 ficaram soropositivos (Tabela 1). Em tempo semelhante, também foi observada soroconversão para os arbovírus Ilhéus (6,2\%), Mayaro (1,1\%) e Oropouche $(1,1 \%)$.
$\mathrm{Na}$ Tabela 2, foi comparado o resultado sorológico dentre as variáveis demográficas pesquisadas (sexo e idade), tanto nas pessoas com anticorpos contra o 17D (em agosto de 1999) como para 0 conjunto daqueles com anticorpos para os arbovírus pesquisados em agosto de 1999. Nesse último grupo, a pessoa amostrada somente foi considerada uma vez e excluindo aquelas com anticorpos para o vírus 17D. Por isto, dos 203 soropositivos (106 para o 17D e 97 para os outros arbovírus), somente foram incluídas 80 pessoas, ou seja, $17(80+17=97)$ pessoas tinham anticorpos para $2(n=13)$ ou $3(\mathrm{n}=4)$ dos arbovírus investigados. Desse modo, foi possível mostrar na Tabela 2 que antes da intervenção (vacina contra a febre amarela), havia a predominância significante $(\mathrm{p}<0,05)$ de pessoas soropositivas para o 17D do sexo masculino (31,9\% vs 22,8\%), mas que após a vacinação as freqüências (respectivamente, 93,1\% vs $91,3 \%)$ de soroconvertidos foram semelhantes $(p>0,62)$. Em relação ao estudo sorológico da amostra de agosto de 1999, as pessoas do sexo masculino foram também mais freqüentemente $(\mathrm{p}<0,005)$ soropositivas $(26,6 \%$ vs $14,8 \%)$ para o conjunto de arbovírus. Quanto à idade, os soropositivos para o 17D em agosto de $1999(\mathrm{p}<0,001)$ e para o conjunto dos arbovírus $(\mathrm{p}<0,001)$ apresentaram médias de idade significativamente maiores (Tabela 2). No entanto, entre aqueles inicialmente soronegativos $(n=145)$, na amostra de agosto de 1999 e também avaliados em janeiro de 2000 , foram semelhantes $(p>0,46)$ as médias das idades dos soropositivos e negativos (Tabela 2 ).

Tabela 2 - Resultados das pesquisas de anticorpos contra o vírus vacinal da febre amarela (17D), antes (1999) e depois (2000) da campanha de vacinação, e para o conjunto dos arbovírus pesquisados em Rio Branco (Acre), segundo o sexo e a idade.

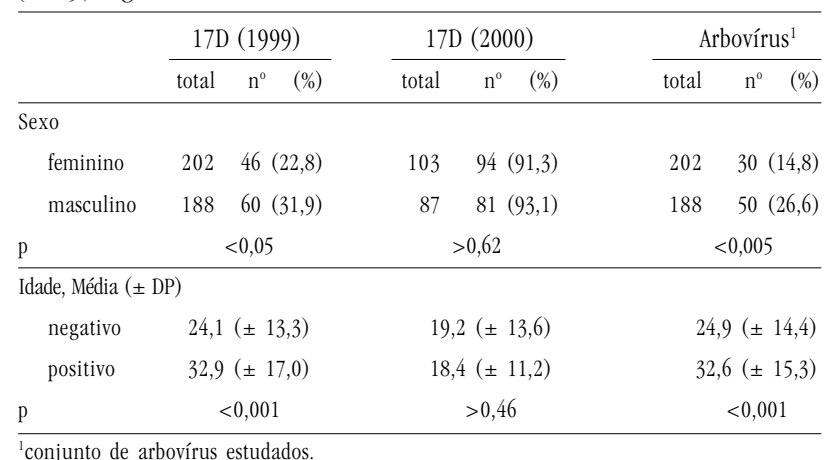

Não foi estudado o tempo de residência no Estado do Acre, mas a distribuição do resultado sorológico para o conjunto dos arbovírus pesquisados teve frequiências de soropositivos semelhantes $(\mathrm{p}>0,18)$ quanto à naturalidade: Estado do Acre (19,6\% ou 62/316); outros Estados amazônicos (16,7\% ou 6/36) ou de outras unidades federadas (31,6\% ou 12/38). Também, entre os naturais do Estado do Acre $(\mathrm{n}=316)$, não foram observadas diferenças significantes $(\mathrm{p}>0,20)$ nas frequêencias de soropositivos (conjunto de arbovírus) entre aqueles naturais de municípios do Vale do Acre (18,3\% ou 47/257) versus os do Vale do Juruá (25,4\% ou 15/59). Entre os naturais do Vale do Acre $(n=257)$, grande parte $(80,9 \% ; n=208)$ era da cidade de Rio Branco.

0 valor preditivo-positivo da história de vacinação prévia, em relação à pesquisa de anticorpos anti-17D nas amostras de agosto de 1999, foi baixo - de 30,6\% (64/209) -, ao contrário do valor 
preditivo-negativo de $77,4 \%$ (89/115), mas as diferenças observadas (Tabela 3) não alcançaram significância estatística ( $>00,24)$. Quando foi levantada a história de vacinação contra 0 vírus vacinal 17D, em outubro de 1999, e comparada à pesquisa de anticorpos anti-17D na amostra sérica de janeiro de 2000, o valor preditivopositivo foi elevado de $92,1 \%(152 / 165)$, sendo baixo (8,3\%) o valor preditivo-negativo (Tabela 3).

A Tabela 3 também mostra que foi muito baixa $(0,3 \%)$ a freqüência de pessoas que portavam a caderneta de vacinação, quando da primeira dose da Campanha Estadual (agosto de 1999) e que em janeiro de 2000, cinco meses após, somente 39,5\% apresentaram a caderneta de vacinação, mas sendo semelhante ( $>0,60)$ a proporção de soropositivos entre os portadores da caderneta (93,3\%) e os não-portadores (91,3\%).

Nenhuma pessoa, com história de vacinação (17D) em outubro de 1999 e pesquisada em janeiro de 2000, referiu qualquer agravo à saúde nos três meses subseqüentes ou a algum evento adverso, relacionado à vacina, de intensidade moderada ou grave.

\section{DISCUSSÃO}

Esse é o primeiro estudo realizado no Estado do Acre, sobre a prevalência de portadores de anticorpos contra os arbovírus mais prevalentes na região Norte do Brasil ${ }^{1718}{ }^{19}$. Talvez, pela procedência e naturalidade predominantemente urbana da amostra populacional, a freqüência de soropositivos $(<6 \%)$ para grande parte dos vírus estudados (Mayaro, Mucambo, Ilhéus, Rocio, Saint Louis, Oropouche, Caraparu e Catu) foi inferior à esperada, considerando os resultados de outros estudos sorológicos realizados na região amazônica ${ }^{17}$. É preciso considerar que não devem ser raros os prováveis contatos (e.g. lazer e ocupacionais) com áreas de florestas nativas, inclusive entre aqueles nascidos na cidade de Rio
Branco, o que muito mais provavelmente ocorre entre os nascidos em cidades de menor porte do Estado do Acre. No entanto, o encontro de mais soropositivos $(31,6 \%$ vs $<20 \%)$ entre os não-naturais de Estados amazônicos, apesar da ausência de significado estatístico, pode evidenciar a maior exposição desses migrantes em atividades extrativistas ou vinculadas à agricultura ou à agroindústria.

Na população estudada, a soroconversão observada para os vírus Ilhéus (6,2\%), Mayaro (1,1\%) e Oropouche (1,1\%), entre a primeira e a segunda amostra sérica, evidencia a provável circulação desses vírus ou outro(s) antigenicamente relacionado(s). Considerando as características da população avaliada, especialmente o efeito da amplitude da faixa etária e do maior contingente de naturais da cidade de Rio Branco, essas incidências, no período de 5 meses, podem ser classificadas como de valores entre médios a elevados. No entanto, na região Norte do Brasil, não há conhecimento sobre estudo avaliando a incidência de alguma infecção por arbovírus.

Coerentemente, as pessoas com anticorpos para o conjunto dos arbovírus estudados foram mais freqüentemente do sexo masculino e de maior idade, evidenciando provavelmente a maior exposição dessas pessoas às áreas de maior circulação dos vírus estudados, onde são próprias para as atividades ocupacionais extrativistas, agrícolas ou de lazer (e.g. caça e pesca). Em publicações anteriores, a freqüência de soropositivos para anticorpos contra esses arbovírus aumentou, proporcionalmente, ao aumento da idade ${ }^{22}{ }^{23}$, o que pode ter associação com o tempo de maior exposição nas atividades de maior risco para adquirir a infecção. No entanto, quanto ao sexo, as observações são variáveis conforme a população estudada ${ }^{22}$ e, talvez isto se explique, por questões de gênero ou, mais especificamente, porque as mulheres têm menos rotineiramente atividades vinculadas às áreas de floresta tropical.

Como registrado, ao longo de 1999, pela Secretaria de Estado da Saúde e Saneamento do Estado do Acre (SESSACRE), os casos de

\begin{tabular}{|c|c|c|c|c|c|c|}
\hline \multirow{4}{*}{ Variável } & \multicolumn{6}{|c|}{ Pesquisa de anticorpos, n(\%) } \\
\hline & \multicolumn{3}{|c|}{ 17D (1999) } & \multicolumn{3}{|c|}{ 17D (2000) } \\
\hline & positivo & negativo & Total & positivo & negativo & total \\
\hline & $\mathrm{n}^{0}(\%)$ & $\mathrm{n}^{0}(\%)$ & $\mathrm{n}^{0}(\%)$ & $\mathrm{n}^{0}(\%)$ & $\mathrm{n}^{0}(\%)$ & $\mathrm{n}^{0}(\%)$ \\
\hline \multicolumn{7}{|c|}{ História de } \\
\hline \multicolumn{7}{|c|}{ Vacina 17D (prévia) } \\
\hline $\operatorname{sim}$ & $64(30,6)$ & $145(69,4)$ & $209(53,6)$ & - & - & - \\
\hline não & $26(22,6)$ & $89(77,4)$ & $115(29,5)$ & - & - & - \\
\hline \multirow[t]{2}{*}{ NSI* } & $16(24,2)$ & $50(75,8)$ & $66(16,9)$ & - & - & - \\
\hline & & $r>0,24$ & & & & \\
\hline \multicolumn{7}{|c|}{ História de } \\
\hline \multicolumn{7}{|c|}{ Vacina 17D (em 1999) } \\
\hline $\operatorname{sim}$ & - & - & - & $152(92,1)$ & $13(7,9)$ & $165(86,9)$ \\
\hline não & - & - & - & $22(91,7)$ & $2(8,3)$ & $24(12,6)$ \\
\hline \multirow[t]{2}{*}{ NSI* } & - & - & - & $1(100,0)$ & 0 & $1(0,5)$ \\
\hline & & & & & $r>0,93$ & \\
\hline \multirow{2}{*}{\multicolumn{7}{|c|}{$\begin{array}{l}\text { Caderneta de } \\
\text { vacinação (vacina 17D) }\end{array}$}} \\
\hline & & & & & & \\
\hline $\operatorname{sim}$ & $1(100,0)$ & 0 & $1(0,3)$ & $70(93,3)$ & $5(6,7)$ & $75(39,5)$ \\
\hline \multirow[t]{2}{*}{ não } & $105(27,0)$ & $284(73,0)$ & $389(99,7)$ & $105(91,3)$ & $10(8,7)$ & $115(60,5)$ \\
\hline & & & & & $r>0,60$ & \\
\hline
\end{tabular}

*NSI: não sabia informar. 
dengue foram importados. No entanto, em novembro de 1999, houve os primeiros registros de dengue na cidade boliviana de Cobija $\mathrm{a}^{4}$. Portanto, as soroprevalências dos DEN-1 (0,3\%) e DEN-2 (4,1\%) observadas nas amostras de agosto de 1999, provavelmente, espelham aquele momento epidemiológico. Já no ano 2000, na cidade de Rio Branco foram notificados 2.178 casos de dengue, especialmente nos meses de novembro $(n=326)$ e dezembro $(\mathrm{n}=525)$, e com a confirmação de 1.283 casos (SESSACRE, dados não-publicados). Também no ano 2000, de janeiro a dezembro, os índices de infestação predial pelo Aedes aegypti na cidade de Rio Branco variaram de $0 \%$ a 16,47\% (média de 3,5\%), conforme 0 bairro pesquisado (SESSACRE-DABS, dados não-publicados).

Quando do segundo levantamento soroepidemiológico (janeiro de 2000), a curva epidêmica da dengue poderia estar com a incidência de nível endêmico, mas não ainda em fase de progressão ou que pode ter começado a ocorrer no segundo semestre de 2000. Porque, não só considerando o conhecimento sobre as curvas epidêmicas da dengue ${ }^{23}$, os casos notificados foram mais freqüentes a partir de novembro e dezembro de 2000 e a incidência máxima da epidemia na terceira semana epidemiológica (janeiro) de 2001, simultaneamente pelos sorotipos DEN-1 e DEN-2, quando foram confirmados 410 dos 445 casos notificados na cidade de Rio Branco ${ }^{4}$.

Mais recentemente, nas cidades de Brasiléia e Epitaciolândia, na divisa com a cidade de Cobija (Bolívia), também foram confirmados casos autóctones de DEN-1 e DEN-24. Por isto, vale ressaltar a observação dos $6(3,2 \%)$ casos com anticorpos contra 0 sorotipo DEN-3 em janeiro de 2000, sendo anteriormente (agosto de 1999) soronegativos para esse mesmo sorotipo. Oficialmente, 0 DEN-3 foi isolado no Brasil em dezembro de 2000 na cidade do Rio de Janeiro ${ }^{12}$, seguido por isolamentos subseqüentes ou de epidemias em populações de cidades das regiões Sudeste e Nordeste do Brasil ${ }^{3}$. Portanto, o registro de soropositivos (IH) para o DEN-3 em amostras séricas extraídas em janeiro de 2000 é digno de nota, especialmente porque foram em pessoas residentes em região distante daquelas localidades das regiões Sudeste e Nordeste do Brasil. Contudo, vale também ressaltar, apesar do isolamento geográfico do Estado do Acre, muitas das cidades do Vale do Acre, inclusive Rio Branco, têm grande intercâmbio de pessoas e mercadorias com a cidade de Cobija (Estado de Pando, Bolívia), onde há aeroporto internacional e com possibilidade de comunicação aérea com outros centros urbanos da América Latina e onde há circulação do DEN-3 ${ }^{13}$.

Apesar do Ministério da Saúde do Brasil recomendar, há mais de três décadas, a vacinação contra o vírus vacinal (17D) da febre amarela nas populações residentes na região Norte do País, especialmente aquelas residentes nas pequenas localidades ou em áreas de floresta nativa, onde há maior risco de exposição ao ciclo silvestre do vírus da febre amarela ${ }^{24}$, somente $27,2 \%$ da população estudada tinha soroproteção contra o vírus amaralíco na amostra sérica de agosto de 1999. Isto tem ainda maior relevância, porque é sabido que as pessoas vacinadas mantém títulos de anticorpos protetores por longos períodos de tempo $0^{15}$, mesmo entre residentes de áreas sem programa regular de vacinaçãa ${ }^{22}$. Por outro lado, a baixa frequêencia $(27,2 \%)$ de portadores de anticorpos anti-17D mostrou não só a vulnerabilidade da população ao vírus da febre amarela, antes da campanha de vacinação em massa de 1999, bem como os precários resultados obtidos com as medidas governamentais até então praticadas.

No entanto, nas amostras séricas de três meses após a vacinação em massa contra o vírus 17D, em outubro de 1999, a soroconversão observada foi de $89,7 \%$ entre aqueles inicialmente soronegativos. Nessa Campanha Estadual de Vacinação, do Governo do Estado do Acre e com o apoio da Fundação Nacional de Saúde, foram vacinadas 416.267 pessoas em todo o Estado, correspondendo à época a 82,6\% da população estimada como não-imune ( $n=504.023)$, excluindo os menores de 6 meses de idade e as gestantes. Portanto, essas taxas de cobertura vacinal $(82,6 \%)$ e de soroconversão (89,7\%), bem como o contingente de pessoas previamente imunes $(27,2 \%)$, tornam possível especular que a quase totalidade das pessoas residentes no Estado do Acre em outubro de 1999 esteja imune contra o vírus da febre amarela. Isto provavelmente ocorreu de modo uniforme, no grupo populacional com indicação de receber a vacina, considerando as distribuições semelhantes de sexo e idade dos portadores de anticorpos anti-17D em janeiro de 2000. Ao contrário do observado entre aqueles pesquisados em agosto de 1999, quando predominaram as pessoas do sexo masculino e de maior idade, o que pode evidenciar o efeito dessas pessoas saberem ser mais expostas ao ciclo silvestre da febre amarela e, conseqüentemente, buscaram mais a vacinação.

Não obstante, seria mais indicado o teste de neutralização (TN), por ser mais sensível e específico, para avaliar a soroconversão pela vacina antiamarílica e usando como substrato cultura de células ou camundongos recém-nascidos (PFC Vasconcelos, informação pessoal). No entanto, o TN, se comparado a teste de inibição da hemaglutinação, tem como principais limitações em estudos soroepidemiológicos o custo mais elevado e também, especialmente se for usados camundongos recém-nascidos, o tempo despedido para conclusão dos exames sorológicos, além de requerer biotério com capacidade de fornecer grande número de animais.

0 custo-benefício da elevada taxa de cobertura vacinal na população da cidade de Rio Branco, e por extensão do Estado do Acre, deve ser também avaliado considerando a proteção duradoura oferecida por essa vacina, ou de pelo menos 10 anos $^{15}$, e 0 atual risco de urbanização do vírus da febre amarela ${ }^{11}$, o que tem merecido reiterados alertas as autoridades de saúde do Brasil ${ }^{511} 1624$, decorrente da elevada dispersão do Ae. aegypti em grande parte das cidades brasileiras, à semelhança do observado nas áreas de maior densidade populacional do Estado do Acre.

Adicionalmente, em todo o Estado do Acre não ocorreu aumento da incidência de encefalopatias, de encefalites ou de outro evento adverso conhecido ${ }^{25}$ nos dias subseqüentes à aplicação em massa da vacina 17D (SESSACRE/DABS, dados não-publicados). Entre as 416.267 pessoas vacinadas contra o 17D em outubro de 1999, em todo o Estado do Acre, somente foi notificado um caso (homem, de 26 anos, previamente sadio) que desenvolveu abscesso piogênico no local da aplicação da vacina, que evoluiu para sepse e faleceu, dezesseis dias após a vacinação, com falência múltipla de órgãos (SESSACRE/DABS, dados não-publicados).

Provavelmente pelo efeito do viés de recordação, não houve diferença da soropositividade para o 17D entre aqueles com ou sem história de vacinação prévia a agosto de 1999. Ao contrário, possivelmente por ser um evento mais recente, a história de vacinação (em outubro de 1999) foi muito mais lembrada pelos 
soropositivos para o 17D na amostra sérica de janeiro de 2000. Contudo, além do baixo valor preditivo-positivo da história de vacinação, observada no levantamento de agosto de 1999, não é hábito da população guardar a caderneta de vacinação ou mesmo levá-la à unidade de imunização por ocasião da aplicação de uma nova dose de vacina, isto porque somente uma $(0,3 \%)$ pessoa a apresentou quando da aplicação da primeira dose (agosto de 1999) da vacina contra 0 vírus da hepatite B. Essa situação fica ainda mais evidente ao constatar que somente $39,5 \%$ das pessoas tinham aquela caderneta em janeiro de 2000, ou seja, isto após 5 meses do início da Campanha Estadual de Intensificação do Calendário de Imunizações, que mobilizou ampla parcela da população do Estado do Acre, e com maciça divulgação nos vários tipos de mídia.

Como estes resultados observados sobre a caderneta de vacinação são semelhantes aos descritos nos Estados da Bahia ${ }^{20}$ e de Minas Gerais $^{1}$, há fortes indícios sobre a inadequação dessa prática de registro e, por isto mesmo, os gestores do Sistema Único de Saúde deveriam estudar melhor estratégia de registro e/ou de armazenamento de dados, de mais fácil verificação, e que cobrisse, ao menos, as vacinas constantes do Programa Nacional de Imunização.

Em conclusão, a população estudada tem aparentemente menor exposição aos arbovírus mais prevalentes na região amazônica brasileira e, apesar de potencialmente mais exposta ao vírus da febre amarela, tinha, antes da campanha de vacinação, baixa taxa de cobertura vacinal contra o vírus 17D. De outro lado, os índices atuais de infestação do Ae aegypti, os determinantes econômicos e sócioculturais e a evidência sorológica de circulação do DEN-3, tornam a população do Estado do Acre potencialmente exposta a outra epidemia de dengue pelo sorotipo 3 (DEN-3).

\section{REFERÊNCIAS BIBLIOGRÁFICAS}

1. Ambrósio MR, Fernandes EC. Análise do cartão de imunizações em escolares de Uberlândia. Revista Cearense de Pediatria 1: 17, 1998.

2. Freitas-Carvalho J, Viana S, Darub R, Farias E, Rocha G, Galvão-Castro B, TavaresNeto J. Soroprevalência para retrovírus em uma amostra da população de Rio Branco (Acre). Revista Baiana de Saúde Pública 26, 2002.

3. Fundação Nacional de Saúde. Casos de Dengue. Brasil por ano - série histórica. Ministério da Saúde/Fundação Nacional de Saúde (FUNASA), Centro Nacional de Epidemiologia (CENEPI), Brasília. Disponível em <www.funasa.gov.br>, 2002.

4. Guimarães MH. Inquérito soroepidemiológico de dengue em dois municípios do Estado do Acre, fronteira Brasil-Bolívia. Dissertação de Mestrado, Universidade Federal da Bahia, Salvador, BA, 2002

5. Hervé J-P, Dégallier N, Rosa APAT, Sá Filho GC. A febre amarela silvestre no Brasil e os riscos de propagação urbana. Hiléia Médica, Belém 7: 31-40, 1985.

6. Instituto Evandro Chagas. Relatório do Instituto Evandro Chagas de 1968. Instituto Evandro Chagas: Belém, p. 155-161, 1968.

7. Instituto Evandro Chagas. Relatório do Instituto Evandro Chagas de 1974 - 1975. Instituto Evandro Chagas: Belém, p. 29-31, 1975.

8. Instituto Evandro Chagas. Relatório do Instituto Evandro Chagas de 1976 - 1977. Instituto Evandro Chagas: Belém, p. 28-29, 1977.

9. Iversson LB, Rosa APAT, Rosa JFST, Costa CS. Estudos sorológicos para pesquisa de anticorpos de arbovírus em população humana da região do Vale do Ribeira. III. Inquérito em cobitantes com soros de encefalite por flavivírus Rocio. Revista de Saúde Pública 16: 160-170, 1982.
10. Karabatsos N. International catalogue of arboviruses including certain other viruses of vertebrates. 3 ed., American Society of Tropical Medicine and Hygiene: San Antonio, 1985.

11. Mondet B, Rosa APAT, Vasconcelos PFC. Les risques d'épidémisation urbaine de la fièvre au Brésil par les vectures de la dengue. Bulletin de la Societé de Pathologie Exotique 89: 107-114, 1996.

12. Nogueira RMR, Miagostovich MP, Filipis AMB, Pereira MAS, Schatzmayer HG.Dengue virus type 3 in Rio de Janeiro, Brazil. Memórias do Instituto Oswaldo Cruz 96: 925-926, 2002.

13. Organização Panamericana da Saúde, Organização Mundial da Saúde. $128^{a}$ Sessão do Comitê Executivo Prevenção e Controle da Dengue. CE 128/15, 3p. 2001. Disponível em: <http/:www.paho.org/spanish/sha perfiles.htm>, 2002

14. Panamerican Health Organization. Dengue and dengue hemorrhagic fever in the Americas: guidelines for prevention and control. Washington, DC., Panamerican Health Organization, Scientific Publication n ${ }^{\circ}$ 548, 1994.

15. Pinheiro FP, Gomes MLC. Immune response to yellow fever vaccine. In Symposium on Yellow Fever. Instituto Evandro Chagas: Belém (Brazil), 1980.

16. Prata A, Rosa APAT, Teixeira G, Coelho ICB, Tavares-Neto J, Dias J, Figueiredo LTM, Dietze R, Valls R, Maris S, Alecrim W. Condutas terapêuticas e de suporte no paciente com dengue hemorrágico. Informe Epidemiológico do SUS 6: 87$101,1997$.

17. Rosa APAT, Rosa JFST, Pinheiro FP, Vasconcelos PFC. Arboviroses. In: Leão RNQ (coord), Doenças Infecciosas e Parasitárias: Enfoque amazônico. CEJUP/Universidade do Estado do Pará: Belém, p. 208-225, 1997.

18. Rosa JFST, Rosa APAT, Vasconcelos PFC, Pinheiro FP, Rodrigues SG, Rosa EST, Dias LB, Cruz ACR. Arboviruses isolated in the Evandro Chagas Institute, including some described for the first time in the brazilian amazon, their known hosts, and their pathology for mam. In: Travassos APA, Vasconcelos PFC, Rosa JFST (eds), An Overview of Arbovirology in Brazil and Neighbouring Countries. Instituto Evando Chagas: Belém, p. 19-31, 1998

19. Rosa APAT, Turell MJ, Watts DM, Powers AM, Vasconcelos PFC, Jones JW, Klein TA, Dohm DJ, Shope RE, Degallier N, Popov VL, Russel Kl, Weaver SC, Guzman H, Calampa C, Brault AC, Lemon AP, Tesh RB. Trocara vírus: a newly recognized Alphavirus (Togaviridae) isolated from mosquitoes in the amazon basin. American Journal of Tropical Medicine and Hygiene 64: 93-97, 2001.

20. Santos-Torres S, Straatmann A, Mota K, Vasconcelos PFC, Rosa APAT, TavaresNeto J. Estado imune contra o vírus vacinal (17D) da febre amarela em duas populações do Estado da Bahia. Revista da Sociedade Brasileira de Medicina Tropical 33: 39-46, 2000

21. Shope RE. The use of a microhemagglutination-inhibition test to follow response after arthropod-borne virus infection in a community of forest animals. Anais de Microbiologia 11 (Parte A): 167-171, 1963.

22. Tavares-Neto J, Rosa APAT, Vasconcelos PFC, Costa JML, Rosa JFST, Marsden PD. Pesquisa de anticorpos para arbovírus no soro de residentes no povoado de Corte de Pedra, Valença, Bahia. Memórias do Instituto Osvaldo Cruz, Rio de Janeiro 81: 351-358, 1986.

23. Vasconcelos PFC. Estudo de epidemias de dengue: uso e significado dos inquéritos soro-epidemiológicos transversais. Tese de Doutorado, Faculdade de Medicina da Universidade Federal da Bahia, 1999.

24. Vasconcelos PFC, Costa ZG, Rosa EST, Luna E, Rodrigues SG, Barros VLRS, Dias JP, Monteiro HAO, Oliva OFP, Vasconcelos HB, Oliveira RC, Sousa MRS, Barbosa da Silva J, Cruz ACR, Martins EC, Travassos da Rosa JFS. Epidemic of jungle yellow fever in Brazil, 2000: implications of climatic alterations in disease spread. Journal of Medical Virology 65: 598-604, 2001.

25. Vasconcelos PFC, Luna EJ, Galler R, Silva LJ, Coimbra TL, Barrros VLR, Monath TP, Rodrigues SG, Laval C, Costa ZG, Vilela MFG, Santos CLS, Papaiordanou CM0, Alves VAF, Andrade LD, Sato HK, Rosa EST, Froguas GB, Lacava E, Almeida LMR, Cruz ACR, Rocco IM, Santos RTM, Oliva OFP and the Brazilian Yellow Fever Vaccine Evaluation Group. Serious adverse events associated with yellow fever 17DD vaccine in Brazil: a report of two cases. Lancet 358: 91-97, 2001. 